\title{
Mechanism of Chlorination Process: From Propanoic Acid to $\alpha$-Chloropropanoic Acid and Byproducts Using Propanoic Anhydride as Catalyst
}

\author{
Da Xue, ${ }^{1}$ Yuna Li, ${ }^{1}$ Jisheng Liu, ${ }^{1}$ Chuan Gao, ${ }^{2}$ Jianwei Xue, ${ }^{1}$ Fuxiang Li, ${ }^{1}$ and Zhiping Lv ${ }^{1}$ \\ ${ }^{1}$ College of Chemistry and Chemical Engineering, Taiyuan University of Technology, Taiyuan 030024, China \\ ${ }^{2}$ Faculty of Arts and Social Sciences, The University of Sydney, Sydney, NSW, Australia \\ Correspondence should be addressed to Jianwei Xue; xuejianwei@tyut.edu.cn
}

Received 25 February 2017; Accepted 7 May 2017; Published 4 June 2017

Academic Editor: Gulaim A. Seisenbaeva

Copyright (C) $2017 \mathrm{Da}$ Xue et al. This is an open access article distributed under the Creative Commons Attribution License, which permits unrestricted use, distribution, and reproduction in any medium, provided the original work is properly cited.

\begin{abstract}
This article reports on findings regarding the mechanism of chlorination process. In this experiment, propanoic acid was chlorinated to $\alpha$-chloropropanoic acid in a lab-scale glass tube reactor operating at $130^{\circ} \mathrm{C}$. Propanoic anhydride and concentrated sulfuric acid were, respectively, used as the catalyst and the promoter. This experiment adopted the DFT method to calculate the activation energy of routes for the synthesis $\alpha$-chloropropanoic acid, $\beta$-chloropropanoic acid, $\alpha$, $\alpha$-dichloropropanoic acid, and $\alpha$, $\beta$ dichloropropanoic acid. The results showed that the main route of $\alpha$-chloropropanoic acid was formed through an ionic mechanism when propanoic anhydride was used as the catalytic agent. Activation energy of 1-propen-1-ol,1-chloro, which was formed from 1prop-anol,1-chloro-, was the highest in the process of ionic mechanism. In addition, $\alpha, \alpha$-dichloropropanoic acid was formed via a consecutive ionic chlorination path from $\alpha$-chloropropanoic acid. $\beta$-Chloropropanoic acid was produced from propanoic acid through a chlorination radical mechanism. $\alpha, \beta$-Dichloropropanoic acid was formed via a consecutive radical chlorination path.
\end{abstract}

\section{Introduction}

$\alpha$-Chloropropanoic acid, as a kind of active organic chemical, has been widely used to produce pesticides, dyes, chemicals of agriculture and forestry, intermediates, and so forth. It plays an important role in the fine chemical industry. Due to the existence of a chlorine atom in the $\alpha$-chloropropanoic acid's molecular structure, its acidic density and reactivity are stronger than those of propanoic acid, which is more active in chemical reactions [1-4].

Sioli et al. [5] proposed the acid-catalyzed enolization of ionic mechanism for the first time to explore the synthesis of $\alpha$-chloropropanoic acid. Paatero et al. [6] found that acid catalysis was a process of autocatalysis when using chlorosulfonic acid as an enolizing agent. Salmi et al. [7, 8] and Mäki-Arvela et al. [9] identified an autocatalysis effect. They found that the monochloropropanoic acid created in the reaction was much stronger than the propanoic acid [10], which led to an increasing rate of acid catalysis and autocatalysis. The autocatalytic kinetic was explained by a reaction involving the acid-catalyzed enolization of the key intermediate, propanoyl chloride, as a rate-determining step.

Ogata et al. [11] and Ham et al. [12] found that the generation of $\beta$-chloropropanoic acid was by radical chlorination in the $\alpha$-chloropropanoic acid synthesis process. Paatero et al. [6] identified that the formation route of $\alpha, \alpha$ dichloropropanoic acid was the same as $\alpha$-chloropropanoic acid formation, the parallel acid-catalyzed enolization mechanism. Mäki-Arvela et al. [10] also found that $\alpha, \alpha$ dichloropropanoic acid generation has two routes: the ionic mechanism and the radical mechanism. There exists a competition between these two mechanisms. $\alpha, \beta$-Dichloropropanoic acid was formed through further chlorination of $\alpha$-chloropropanoic acid.

However, the reaction mechanisms of byproducts, for instance, the $\alpha, \alpha$-dichloropropanoic acid, have received different opinions. Thus, this article aims to report on findings on the reaction mechanism of chlorination products through experimenting with propanoic acid chlorinated by using the density function method with $\mathrm{Dmol}^{3}$ program of Materials 
Studio 5.5. The results could contribute to production optimization of $\alpha$-chloropropanoic acid.

\section{Experimental and Calculation Section}

2.1. Experimental. Propanoic acid chlorination was carried out in a homemade glass tube equipped with a magnetic stirring apparatus and an oil bath heater with a temperature control. Chlorine gas was dispersed into the reaction mixture which was metered by a rotameter. A reflux condenser equipped with low temperature cooling circulating pump was placed on the top of the reactor. The gaseous compounds passed through water, sodium bicarbonate solution, and concentrated sodium hydroxide solution before being released to the air.

The propanoic acid to be chlorinated was placed in the reaction vessel. A slightly excess chlorine feed was introduced, and the liquid phased was heated to the desired reaction temperature. A certain amount of propanoic anhydride was added. Samples of the liquid phase were analyzed with gas chromatograph after esterification [10].

2.2. Calculation Methods. Density functional theory method quantum chemistry calculation was adopted and the calculations were performed by using the $\mathrm{Dmol}^{3}$ program mounted on Materials Studio 5.5 package. All the reactants and products in the chlorination reaction were optimized and their stable structures were obtained at the same time. All transition states of the reactions were trialed and searched carefully by using an LST/QST method, getting the primitive activation energy and the heat of reaction. The nonlocal exchange and correlation energies were calculated by the PW91 function of the generalized gradient approximation (GGA) [13] and a double numerical plus polarization (DNP) basis set in the level of All Electron. The convergence criteria included threshold values of $1 \times 10^{-5}$ Hartree, 0.02 Hartree per $\mathrm{nm}$, and $0.0005 \mathrm{~nm}$ for energy, force, and displacement convergence, respectively, while the self-consistent field (SCF) density convergence threshold value was specified as $1 \times 10^{-6}$ Hartree. Fermi smearing of 0.005 Hartree was employed to improve the computational performance, and the solvent effect was also considered during the calculations. The geometries of all stationary points were optimized at this level.

\section{Results and Discussion}

3.1. The Experimental Results. The experiment first investigated the effect of propanoic acid catalytic chlorine (see Figure 1) in the condition of $15 \mathrm{ml}$ propanoic acid, $5 \mathrm{ml}$ propanoic anhydride, $130^{\circ} \mathrm{C}$ reaction temperature, and $40 \mathrm{ml} / \mathrm{min}$ chlorine flow rate with micro excess. The generation of $\alpha$ chloropropanoic acid was little in the first $30 \mathrm{~min}$ and increased rapidly during the period from $30 \mathrm{~min}$ to $150 \mathrm{~min}$. Its generation did not increase obviously thereafter. The generation of $\beta$-chloropropanoic acid increased steadily in the first $150 \mathrm{~min}$ but increased slowly from $150 \mathrm{~min}$ to $360 \mathrm{~min}$. The generation of $\alpha, \alpha$-dichloropropanoic acid increased quite



FIgURE 1: The reaction products change over time at $130^{\circ} \mathrm{C}$.

slowly before $250 \mathrm{~min}$ and increased rapidly in the later reaction.

In order to verify the catalytic principle, $0.4 \mathrm{ml}$ concentrated sulfuric acid was added to propanoic anhydride catalytic chlorination to observe the effect of the chlorination reaction, compared with the control experiment. Chloride products were analyzed by gas chromatography (Table 1 ). It was found that the generation of $\alpha$-chloropropanoic acid increased obviously, while the generation of both $\beta$-chloropropanoic acid and $\alpha, \alpha$-dichloropropanoic acid reduced after concentrated sulfuric acid was added. Also, the generation of $\alpha$-chloropropanoic acid (Table 1, Entry $\alpha$ MCA (\%)) increased rapidly in the first $90 \mathrm{~min}$, increased slowly from $90 \mathrm{~min}$ to $150 \mathrm{~min}$, and barely increased from $150 \mathrm{~min}$ to $180 \mathrm{~min}$. The generation of $\beta$-chloropropanoic acid (Table 1, Entry $\beta$-MCA (\%)) shrank with time. The generation of $\alpha, \alpha$-dichloropropanoic acid (Table 1, Entry $\alpha, \alpha$-DCA (\%)) increased in the first $30 \mathrm{~min}$ but reduced from $30 \mathrm{~min}$ to $180 \mathrm{~min}$.

3.2. Synthesis Mechanism of $\alpha$-Chloropropanoic Acid. In order to investigate the formation route of $\alpha$-chloropropanoic acid, two possible reaction paths were constructed: the radical chlorination mechanism and ionic chlorination mechanism (Scheme 1). Path 1 is the formation route of $\alpha$ chloropropanoic acid via radical chlorination mechanism (Scheme 1; see (1)). Path 2 is the formation route of $\alpha$-chloropropanoic acid via ionic chlorination mechanism (Scheme 1; see (2)-(6)).

The configurations of reactants and products were built and the geometry structure was optimized. Transition states were investigated and calculated on the basis of reactants and products. Each reaction transition state was derived from the potential energy surface at the highest point of the potential energy corresponding to the configuration. Frequency analysis showed that these configurations were the only virtual frequency. Energy of reactants, products, and transition states to relevant primitives and the corresponding virtual frequency of the transition state are presented (Table 2). At the same time, energy potential diagrams of the 

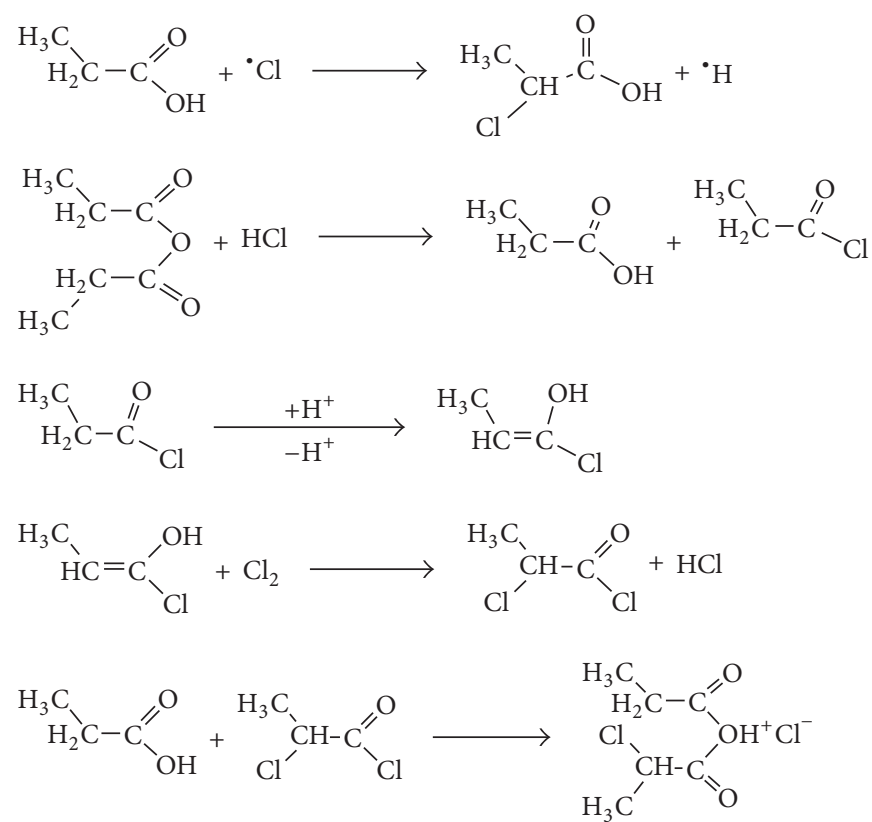<smiles>CCC(=O)[C-](Cl)C(=O)C(C)Cl</smiles>

SCHeme 1: Paths of the generated $\alpha$-chloropropanoic acid.

\begin{tabular}{|c|c|c|c|c|c|}
\hline Catalyst & $T(\min )$ & $\begin{array}{c}\text { Propanoic acid } \\
(\%)\end{array}$ & $\begin{array}{c}\alpha-\mathrm{MCA} \\
(\%)\end{array}$ & $\begin{array}{c}\beta \text {-MCA } \\
(\%)\end{array}$ & $\begin{array}{c}\alpha, \alpha-\mathrm{DCA} \\
(\%)\end{array}$ \\
\hline \multirow{6}{*}{$\begin{array}{l}20 \mathrm{~mol} \% \\
\text { propanoic anhydride }\end{array}$} & 30 & 80.05 & 18.23 & 1.24 & 0.47 \\
\hline & 60 & 62.56 & 34.63 & 1.83 & 0.98 \\
\hline & 90 & 39.74 & 56.73 & 2.11 & 1.42 \\
\hline & 120 & 11.13 & 84.84 & 2.47 & 1.56 \\
\hline & 150 & 5.80 & 89.79 & 2.63 & 1.78 \\
\hline & 180 & 0.51 & 94.57 & 2.91 & 2.01 \\
\hline \multirow{6}{*}{$\begin{array}{l}20 \text { mol } \% \\
\text { propanoic acid } \\
\text { anhydride }+ \\
\text { concentrated sulfuric } \\
\text { acid }\end{array}$} & 30 & 46.52 & 52.18 & 0.59 & 0.71 \\
\hline & 60 & 30.66 & 67.71 & 0.82 & 0.81 \\
\hline & 90 & 13.16 & 85.04 & 0.93 & 0.87 \\
\hline & 120 & 5.8 & 92.18 & 1.04 & 0.98 \\
\hline & 150 & 3.23 & 94.53 & 1.18 & 1.06 \\
\hline & 180 & 0.41 & 97.22 & 1.24 & 1.13 \\
\hline
\end{tabular}

primitive reactions with corresponding reactants, transition states, and products of configuration are shown in Figure 2.

The formation of $\alpha$-chloropropanoic acid via ionic chlorination mechanism is as follows. First, propanoic anhydride conducted initiation (Scheme 1; see (2)) and formed propanoyl chloride. Its reaction activation energy was $12.54 \mathrm{~kJ} / \mathrm{mol}$. Propanoyl chloride then conducted enolization (Scheme 1; see (3)) and formed 1-propen-1-ol,1-chloro, and the corresponding primitive activation energy was $125.73 \mathrm{~kJ} / \mathrm{mol}$. Since then, the double bond in 1-propen-1-ol, 1-chloro was apt to react with chlorine (Scheme 1; see (4)) and formed $\alpha$-chloropropanoyl chloride, and the corresponding primitive activation energy was $20.11 \mathrm{~kJ} / \mathrm{mol}$. Finally, the $\mathrm{OH}$ and $\mathrm{Cl}$ exchange reaction generated $\alpha$-chloropropanoic acid (Scheme 1; see (5) and (6)) and its activation energy was $85.61 \mathrm{~kJ} / \mathrm{mol}$ and $90.48 \mathrm{~kJ} / \mathrm{mol}$. Therefore, reaction (2) was the catalyst initiation reaction among whole reactions (2)-(6) and propanoic acid anhydride formed a real catalyst, propanoyl chloride. The whole reaction process became an acid catalytic reaction once propanoyl chloride was formed. 
TABLE 2: Possible elementary reactions involved in $\alpha$-chloropropanoic acid and byproducts synthesis together with the activation energies $(\mathrm{Ea})$ and reaction energies $(\Delta H)$.

\begin{tabular}{|c|c|c|c|c|}
\hline Step & Chemical reaction & $\begin{array}{c}\text { Frequency } \\
\left(\mathrm{cm}^{-1}\right)\end{array}$ & $\begin{array}{c}\mathrm{Ea} \\
\left(\mathrm{kJ} \cdot \mathrm{mol}^{-1}\right)\end{array}$ & $\begin{array}{c}\Delta H \\
\left(\mathrm{~kJ} \cdot \mathrm{mol}^{-1}\right)\end{array}$ \\
\hline (1) & $\mathrm{C}_{2} \mathrm{H}_{5} \mathrm{COOH}+{ }^{\cdot} \mathrm{Cl} \longrightarrow \mathrm{H}^{+}+\mathrm{CH}_{3} \mathrm{CHClCOOH}$ & -237.61 & 158.37 & 131.50 \\
\hline (2) & $\left(\mathrm{C}_{2} \mathrm{H}_{5} \mathrm{CO}\right)_{2} \mathrm{O}+\mathrm{HCl} \longrightarrow \mathrm{C}_{2} \mathrm{H}_{5} \mathrm{COOH}+\mathrm{C}_{2} \mathrm{H}_{5} \mathrm{COCl}$ & -118.79 & 12.54 & -9.68 \\
\hline (3) & $\mathrm{C}_{2} \mathrm{H}_{5} \mathrm{COCl}+\mathrm{H}^{+} \longrightarrow \mathrm{H}^{+}+\mathrm{CH}_{3} \mathrm{CHCClOH}$ & -117.24 & 125.73 & 117.19 \\
\hline$(4)$ & $\mathrm{CH}_{3} \mathrm{C}_{2} \mathrm{HClOH}+\mathrm{Cl}_{2} \longrightarrow \mathrm{HCl}+\mathrm{C}_{2} \mathrm{H}_{4} \mathrm{ClCOCl}$ & -48.63 & 20.11 & -170.74 \\
\hline$(5)$ & $\mathrm{C}_{2} \mathrm{H}_{4} \mathrm{ClCOCl}+\mathrm{C}_{2} \mathrm{H}_{5} \mathrm{COOH} \longrightarrow \mathrm{C}_{6} \mathrm{H}_{10} \mathrm{O}_{3} \mathrm{Cl}_{2}$ & -161.81 & 85.61 & 19.05 \\
\hline (6) & $\mathrm{C}_{6} \mathrm{H}_{10} \mathrm{O}_{3} \mathrm{Cl}_{2} \longrightarrow \mathrm{C}_{2} \mathrm{H}_{5} \mathrm{COCl}+\mathrm{CH}_{3} \mathrm{CHClCOOH}$ & -138.82 & 90.48 & -116.71 \\
\hline (7) & $\mathrm{C}_{2} \mathrm{H}_{5} \mathrm{COOH}+{ }^{\cdot} \mathrm{Cl} \longrightarrow \mathrm{H}^{+}+\mathrm{CH}_{2} \mathrm{ClCH}_{2} \mathrm{COOH}$ & -343.25 & 217.04 & 146.69 \\
\hline (8) & $\mathrm{CH}_{3} \mathrm{C}_{2} \mathrm{HClOH}+\mathrm{Cl}_{2} \longrightarrow \mathrm{HCl}+\mathrm{CH}_{2} \mathrm{ClCH}_{2} \mathrm{COCl}$ & -294.33 & 110.27 & -187.88 \\
\hline (9) & $\mathrm{CH}_{2} \mathrm{ClCH}_{2} \mathrm{COCl}+\mathrm{C}_{2} \mathrm{H}_{5} \mathrm{COOH} \longrightarrow \mathrm{C}_{6} \mathrm{H}_{10} \mathrm{O}_{3} \mathrm{Cl}_{2}$ & -121.03 & 188.14 & 106.79 \\
\hline (10) & $\mathrm{C}_{6} \mathrm{H}_{10} \mathrm{O}_{3} \mathrm{Cl}_{2} \longrightarrow \mathrm{C}_{2} \mathrm{H}_{5} \mathrm{COCl}+\mathrm{CH}_{2} \mathrm{ClCH}_{2} \mathrm{COOH}$ & -208.36 & 34.54 & -122.72 \\
\hline (11) & $\mathrm{CH}_{3} \mathrm{CHClCOOH}+{ }^{\circ} \mathrm{Cl} \longrightarrow \mathrm{H}^{+}+\mathrm{CH}_{3} \mathrm{CCl}_{2} \mathrm{COOH}$ & -758.10 & 162.64 & 134.13 \\
\hline$(12)$ & $\mathrm{CH}_{3} \mathrm{CHClCOOH}+{ }^{\cdot} \mathrm{Cl} \longrightarrow \mathrm{H}^{+}+\mathrm{CH}_{2} \mathrm{ClCHClCOOH}$ & -486.96 & 180.08 & 138.43 \\
\hline$(13)$ & $\mathrm{CH}_{2} \mathrm{ClCH}_{2} \mathrm{COOH}+{ }^{\circ} \mathrm{Cl} \longrightarrow \mathrm{H}^{+}+\mathrm{CH}_{2} \mathrm{ClCHClCOOH}$ & -887.32 & 178.87 & 153.22 \\
\hline$(14)$ & $\mathrm{CH}_{3} \mathrm{CHClCOCl}+\mathrm{H}^{+} \longrightarrow \mathrm{H}^{+}+\mathrm{CH}_{3} \mathrm{CClCClOH}$ & -1103.93 & 130.81 & 117.22 \\
\hline$(15)$ & $\mathrm{CH}_{3} \mathrm{CClCClOH}+\mathrm{Cl}_{2} \longrightarrow \mathrm{HCl}+\mathrm{CH}_{3} \mathrm{CCl}_{2} \mathrm{COCl}$ & -84.36 & 21.99 & -129.19 \\
\hline$(16)$ & $\mathrm{CH}_{3} \mathrm{CCl}_{2} \mathrm{COCl}+\mathrm{C}_{2} \mathrm{H}_{5} \mathrm{COOH} \longrightarrow \mathrm{C}_{6} \mathrm{H}_{9} \mathrm{O}_{3} \mathrm{Cl}_{3}$ & -69.22 & 82.61 & -168.57 \\
\hline (17) & $\mathrm{C}_{6} \mathrm{H}_{9} \mathrm{O}_{3} \mathrm{Cl}_{3} \longrightarrow \mathrm{CH}_{3} \mathrm{CCl}_{2} \mathrm{COOH}+\mathrm{C}_{2} \mathrm{H}_{5} \mathrm{COCl}$ & -365.41 & 109.73 & -95.67 \\
\hline
\end{tabular}


TS1

TS2

TS3


TS4

TS6

FIGURE 2: Potential energy diagram of $\alpha$-chloropropanoic acid synthesis together with the initial states, transition states, and final states. 

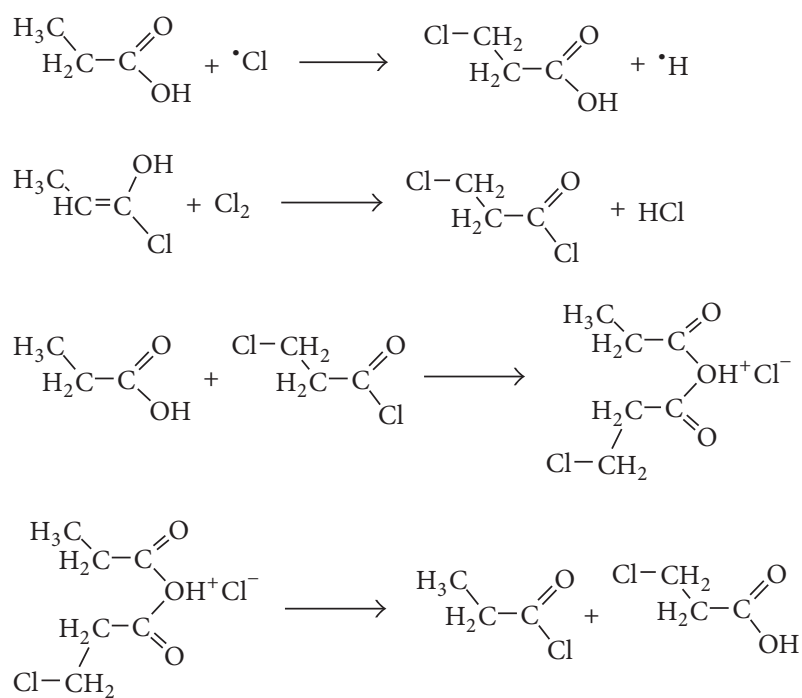

SCHEME 2: Radical chlorination mechanism of byproducts.

More importantly, the acidity of $\alpha$-chloropropanoic acid was stronger than that of propanoic acid, so the acid catalytic reaction was accelerated.

The activation energy $125.73 \mathrm{~kJ} / \mathrm{mol}$ (Scheme 1; see (3)) was the highest as the rate-determining step after propanoyl chloride was formed. It is consistent with the results of Paatero. The results also showed that the formation rate of $\alpha$-chloropropanoic acid was slow at the beginning and was rapid in the middle of the reaction. The reason for it could be that catalyst initiation reaction was slow, and the activation energy of the whole process would reduce once propanoyl chloride was formed. Meanwhile, the rate of acid catalysis and autocatalysis (Scheme 1; see (3)) was accelerated due to the fact that the acidity of $\alpha$-chloropropanoic acid was stronger than that of propanoic acid. Thus, the generation speed of $\alpha$-chloropropanoic acid was accelerated. In addition, the generation of $\alpha$-chloropropanoic acid increased significantly when concentrated sulfuric acid was added. The added $\mathrm{H}^{+}$in the reaction system promoted the progress of acid catalysis and autocatalysis (Scheme 1; see (3)). In turn, it led to the result that the reaction was conducted toward the generation of $\alpha$-chloropropanoic acid. Therefore, it can be drawn from the theoretical calculation and experimental results that the whole process became an acid catalytic reaction when propanoyl chloride was formed. The generation of $\alpha$-chloropropanoic acid could be accelerated as long as propanoyl chloride acid-catalyzed enolization (Scheme 1; see (3)) was expedited. It could also inhibit the generation of $\beta$ chloropropanoic acid and $\alpha, \alpha$-dichloropropanoic acid.

\subsection{Synthesis Ionic Chlorination Mechanism of $\beta$-Chloropro-} panoic Acid. In order to investigate the formation route of $\beta$-chloropropanoic acid, two possible reaction paths were constructed: the radical chlorination mechanism and ionic chlorination mechanism (Scheme 2, Figure 3). Path 1 is the formation route of $\beta$-chloropropanoic acid via radical chlorination mechanism (Scheme 2; see (7)). Path 2 is the

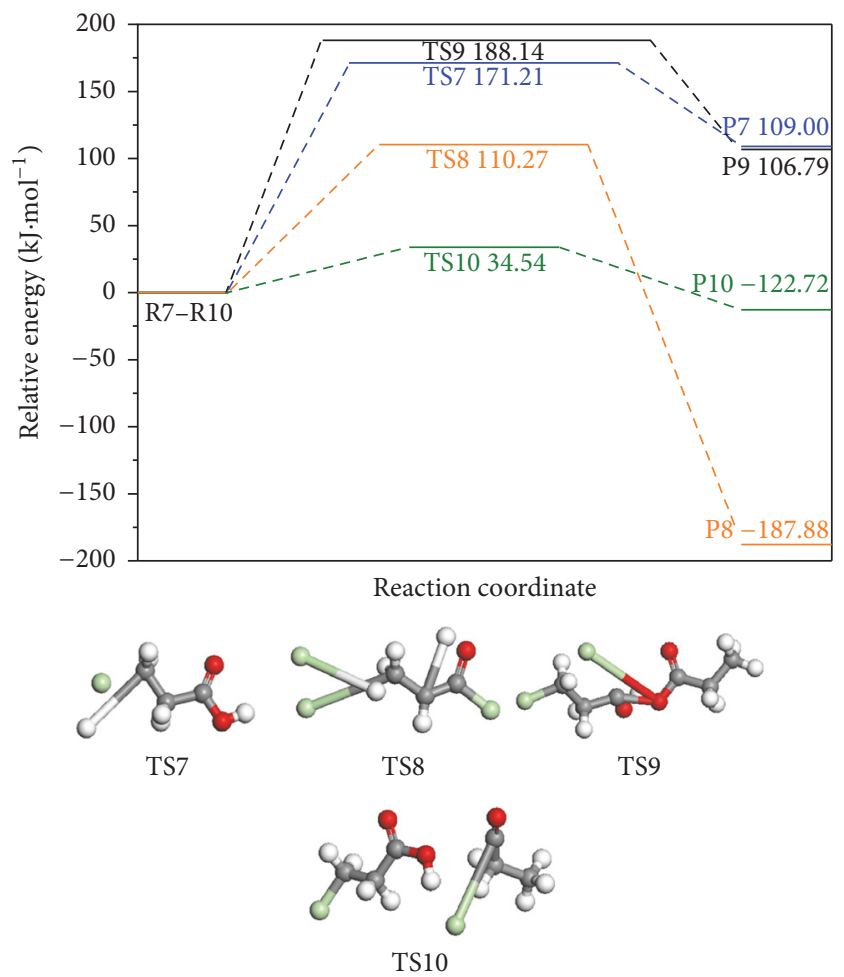

Figure 3: Potential energy diagram of the radical chlorination reactions related of byproducts together with the initial states, transition states, and final states.

formation route of $\beta$-chloropropanoic acid via ionic chlorination mechanism (Scheme 2; see (8)-(10)).

The formation of $\beta$-chloropropanoic acid via ionic chlorination mechanism is as follows. First, propanoyl chloride conducted enolization (Scheme 1; see (3)) and formed 1propen-1-ol,1-chloro, and the corresponding primitive activation energy was $125.73 \mathrm{~kJ} / \mathrm{mol}$. Then, the double bond 


$$
\begin{aligned}
& \mathrm{H}_{3} \mathrm{C} \text { 、 }
\end{aligned}
$$

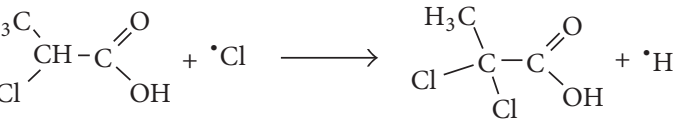

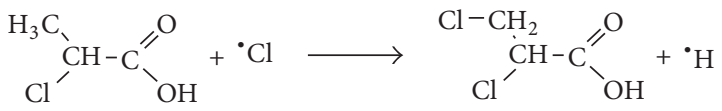

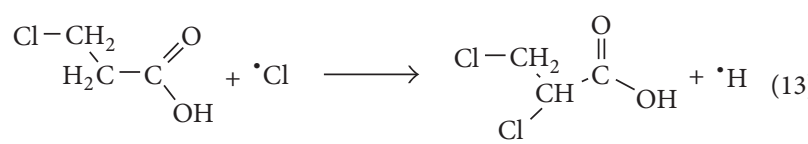

SCHEMe 3: The radical chlorination mechanism of byproducts.

in 1-propen-1-ol, 1-chloro was apt to react with chlorine (Scheme 2; see (8)) and formed $\beta$-chloropropanoyl chloride, and the corresponding primitive activation energy was $110.27 \mathrm{~kJ} / \mathrm{mol}$. Finally, the $\mathrm{OH}$ and $\mathrm{Cl}$ exchange reaction generated $\beta$-chloropropanoic acid (Scheme 2; see (9) and (10)) and its activation energy was $188.14 \mathrm{~kJ} / \mathrm{mol}$ and $34.54 \mathrm{~kJ} / \mathrm{mol}$. Compared to these two kinds of paths which generated $\beta$-chloropropanoic acid and $\alpha$-chloropropanoic acid, the activation energy of the formed $\beta$-chloropropanoic acid (Scheme 2; see (9)) was higher than that of the formed $\alpha$ chloropropanoic acid (Scheme 1; see (6)). Therefore, it is difficult to form $\beta$-chloropropanoic acid by ionic chlorination.

3.4. Radical Chlorination Mechanism of Byproducts. The radical chlorination mechanism consists of successive chlorination steps. Initially, the $\alpha$-chloropropanoic acid and $\beta$-chloropropanoic acid were formed and then further chlorinated to $\alpha, \alpha$-dichloropropanoic acid and $\alpha, \beta$ dichloropropanoic acid (Scheme 3). The activation energies (Ea) and reaction energies $(\Delta H)$ calculation results are shown in Table 1. The energy potential diagram of the primitive reaction and the corresponding reactants, transition states, and products configuration is presented in Figure 4.

The activation energy of radical chlorination reaction which generated $\beta$-chloropropanoic acid (Scheme 2; see (7)) and $\alpha, \alpha$-dichloropropanoic acid (Scheme 3; see (11)) was $171.21 \mathrm{~kJ} / \mathrm{mol}$ and $162.64 \mathrm{~kJ} / \mathrm{mol}$, respectively. They were lower than the activation energy of generated $\alpha, \beta$-dichloropropanoic acid, which were $180.08 \mathrm{~kJ} / \mathrm{mol}$ and $178.87 \mathrm{~kJ} / \mathrm{mol}$ (Scheme 3; see (12)) and $187.87 \mathrm{~kJ} / \mathrm{mol}$ (Scheme 3; see (13)). Therefore, $\beta$-chloropropanoic acid and $\alpha, \alpha$-dichloropropanoic acid are the main byproducts.

The activation energy of generated $\beta$-chloropropanoic acid (Scheme 2; see (7)) was $171.21 \mathrm{~kJ} / \mathrm{mol}$, higher than $125.73 \mathrm{~kJ} / \mathrm{mol}$ (Scheme 1; see (3)), which was the ratedetermining step of generating $\alpha$-chloropropanoic acid. The amount of generated $\beta$-chloropropanoic acid changed with time which was different from $\alpha$-chloropropanoic acid in this experiment. Thus, the generation of $\alpha$-chloropropanoic acid was mainly through the acid-catalyzed enolization route, while $\beta$-chloropropanoic acid was mainly through the radical chlorination route.

Compared to these two kinds of paths which generated $\alpha, \beta$-dichloropropanoic acid, the activation energy of



Reaction coordinate



TS11

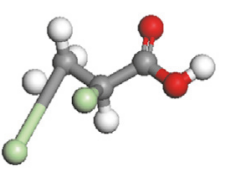

TS12

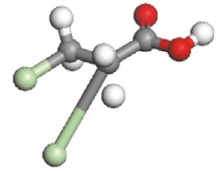

TS13
FIgURE 4: Potential energy diagram of the radical chlorination mechanism of byproducts together with the initial states, transition states, and final states.

the formed $\beta$-chloropropanoic acid (Scheme 2; see (7)) was higher than that of the formed $\alpha$-chloropropanoic acid (Scheme 1; see (3)). Therefore, the formation of $\alpha, \beta$ dichloropropanoic acid could be inhibited through inhibiting the formation of $\beta$-chloropropanoic. But the quantity of $\alpha, \beta$ dichloropropanoic acid is hardly detected in the experiment.

\subsection{Ionic Chlorination Mechanism of $\alpha, \alpha$-Dichloropropanoic} Acid. In order to explore whether the formation between $\alpha, \alpha$-dichloropropanoic acid and $\alpha$-chloropropanoic acid was a consecutive reaction, the paths in ionic chlorination mechanism were designed (Scheme 4). The path (Scheme 4; see (14)), the intermediate in the process generating $\alpha$ chloropropanoyl chloride, can also generate 1-propenol, 1,2dichloro. The consecutive chlorination of 1-propenol, 1,2dichloro with chlorine generated $\alpha, \alpha$-dichlorine propanoyl chloride (Scheme 4; see (15)). $\alpha, \alpha$-Dichlorine propanoyl chloride with propanoic acid generated $\alpha, \alpha$-dichloropropanoic acid (Scheme 4; see (16) and (17)). The $\mathrm{OH}-\mathrm{Cl}$ exchange reaction generated the final product. At the same time, energy potential diagram of the primitive reaction, the corresponding reactants, transition states, and products of configuration is shown in Figure 5.

It was observed that activation energy $130.81 \mathrm{~kJ} / \mathrm{mol}$ (Scheme 4; see (14)) was higher than $109.73 \mathrm{~kJ} / \mathrm{mol}$ (Scheme 4; see (15)) which was the rate-determining step in ionic chlorination mechanism. $\alpha, \alpha$-Dichloropropanoic acid and $\alpha$ chloropropanoic acid were generated at the same time in the process of ionic chlorination mechanism. However, further comparison showed that radical chlorination activation energy $162.64 \mathrm{~kJ} / \mathrm{mol}$ (Scheme 3; see (11)) was higher than $130.81 \mathrm{~kJ} / \mathrm{mol}$ (Scheme 4; see (14)). This implies that radical 



SCHEME 4: The ionic chlorination mechanism of $\alpha, \alpha$-dichloropropanoic acid.

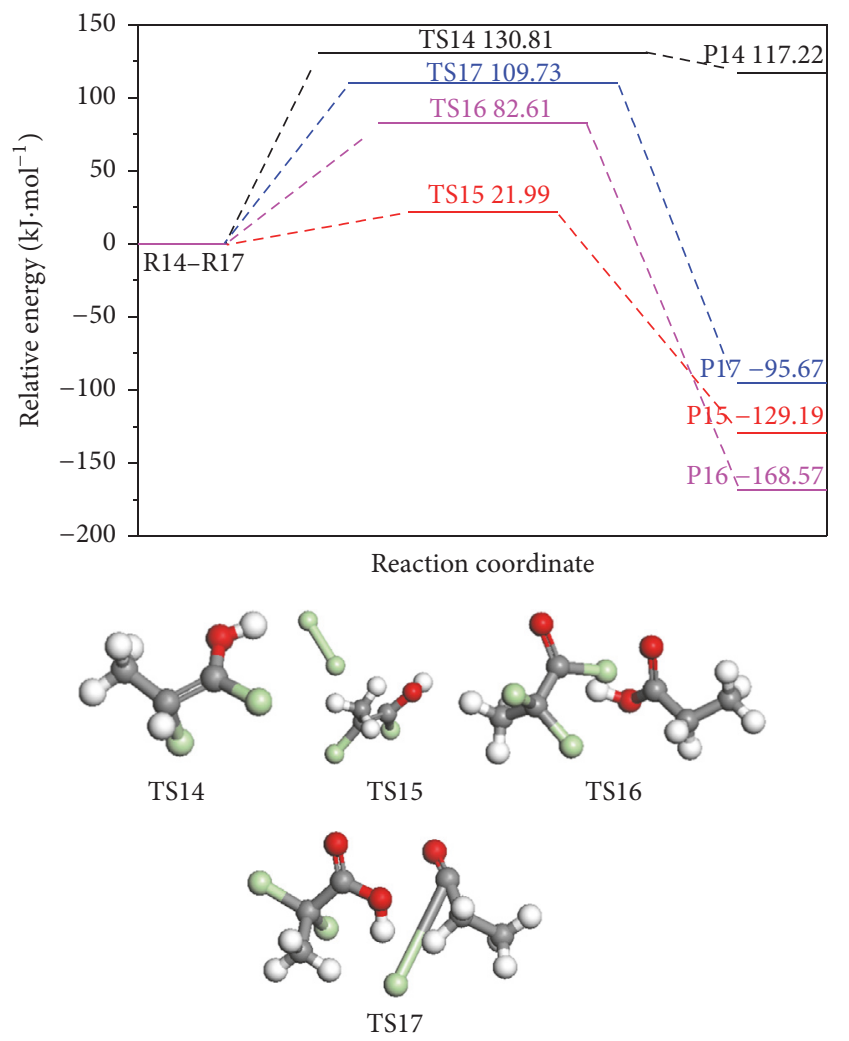

FIGURE 5: Potential energy diagram of ionic chlorination of $\alpha, \alpha$ dichloropropanoic acid together with the initial states, transition states, and final states.

chlorination was not easier to occur than ionic chlorination, which means that ionic chlorination was the main reaction path. Although higher temperature was the main cause of generation of byproducts [10], it was also observed that the generation of $\alpha, \alpha$-dichloropropanoic acid was less before concentrated sulfuric acid was added. This implies that the increase of $\mathrm{H}^{+}$does accelerate the acid-catalyzed path where the product was $\alpha, \alpha$-dichloropropanoic acid. It proved that the generation path of $\alpha, \alpha$-dichloropropanoic acid was ionic chlorination mechanism which also was the cause of the phenomenon of the generation of byproducts. The $\alpha, \alpha$ dichloropropanoic acid increased rapidly under the reaction conditions with higher temperature or excessive chlorine in intermittent industrial manufacture.

\section{Conclusions}

Based on the investigation of the mechanism of chlorination from propanoic acid to $\alpha$-chloropropanoic acid, the results could be summarized as follows:

(1) The activation energy of the ionic mechanism for $\alpha$-chloropropanoic acid formation was lower than that of the radical mechanism. The ionic mechanism involved four reaction routes and was initiated by the acid-catalyzed enolization of propanoyl chloride. Additionally, the activation energy of the ratedetermining step was the process of 1-propanol,1chloro formed 1-propen-1-ol,1-chloro.

(2) The formation route of $\beta$-chloropropanoic acid was mainly through propanoic acid radical chlorination mechanism. $\alpha, \beta$-Dichloropropanoic acid is formed via a consecutive radical chlorination mechanism.

(3) The ionic mechanism of $\alpha, \alpha$-dichloropropanoic acid showed that the ionic chlorination was the main reaction path, and it was not easier for radical chlorination to occur compared with ionic chlorination for generation of $\alpha, \alpha$-dichloropropanoic acid. Hence, the formation route of $\alpha, \alpha$-dichloropropanoic acid and $\alpha$-chloropropanoic acid was consecutive reaction. The formation of $\alpha, \alpha$-dichloropropanoic acid was mainly by $\alpha$-chloropropanoic acid consecutive ionic chlorination mechanism which indicated that $\alpha$-chloropropanoic acid is the key intermediate for $\alpha, \alpha$-dichloropropanoic acid formation process. 


\section{Conflicts of Interest}

The authors declare that there are no conflicts of interest regarding the publication of this paper.

\section{Acknowledgments}

All calculations in this paper were accomplished in the Key Laboratory of Coal Science and Technology, Ministry of Education and Shanxi Province. The authors are indebted to Professor Wang Baojun and Professor Zhang Riguang.

\section{References}

[1] Y. Ogata and S. Watnabe, "Kinetics of the chlorosulfonic acid promoted a iodination of propionic acid," Journal of Organic Chemistry, vol. 44, pp. 2768-2770, 1979.

[2] W. G. Pan and H. J. Zhang, "Study on the Synthesis of L-2Chloropropanoic Acid," Chemical World (China), vol. 50, pp. 40-42, 2010.

[3] T. Salmi, P. Mäki-Arvela, E. Paatero, and R. Byggningsbacka, "Acid catalytic effects in the chlorination of propanoic acid," Journal of Chemical Technology and Biotechnology, vol. 75, pp. 89-97, 2000.

[4] N. V. Tsirul'nikova, N. Podmareva, E. S. Dernovaya, S. K. Belus, and T. S. Fetisova, "Method of producing ethylenediamine-N, N'-di- $\alpha$-propionic acid," Pat. RU2554095, 2016.

[5] G. Sioli, P. M. Spaziante, and L. Giuffre, "Make MCPA in two stages," Hydrocarbon Process, vol. 58, pp. 111-112, 1979.

[6] E. Paatero, T. Salmi, and K. Fagerstolt, "Selective synthesis of $\alpha$-chlorocarboxylic acids," Industrial and Engineering Chemistry Research, vol. 31, no. 11, pp. 2425-2437, 1992.

[7] T. Salmi, E. Paatero, and K. Fagerstolt, "Kinetic model for the synthesis of $\alpha$-chlorocarboxylic acids," Chemical Engineering Science, vol. 48, no. 4, pp. 735-751, 1993.

[8] T. Salmi, E. Paatero, and K. Fagerstolt, "Optimal degree of backmixing in autocatalytic reactions a case study: chlorination of dodecanoic acid," Chemical Engineering Research and Design, vol. 71, no. 5, pp. 531-542, 1993.

[9] P. Mäki-Arvela, T. Salmi, E. Paatero, and R. Sjöholm, "Selective synthesis of $\alpha$-chloropropanoic acid," Industrial and Engineering Chemistry Research, vol. 34, no. 6, pp. 1976-1993, 1995.

[10] P. Mäki-Arvela, T. Salmi, and E. Paatero, "Kinetics of the chlorination of propanoic acid in the presence of chlorosulphonic acid," Chemical Engineering Science, vol. 50, no. 14, pp. 22752288, 1995.

[11] Y. Ogata, T. Harada, K. Matsuyama, and I. Kazuo, " $\alpha$ Chlorination of aliphatic acids by molecular chlorine," Journal of Organic Chemistry, vol. 40, no. 20, pp. 2960-2962, 1975.

[12] J. S. Ham, M. K. Davis, and J. S. Song, "The radical trapping effect of chlorine has been studied by means of electron paramagnetic resonance," Journal of Polymer Science, Polymer Physics Edition, vol. 11, 217 pages, 1973.

[13] C. Xia, L. Ju, Y. Zhao et al., "Heterogeneous oxidation of cyclohexanone catalyzed by TS-1: Combined experimental and DFT studies," Cuihua Xuebao/Chinese Journal of Catalysis, vol. 36, no. 6, pp. 845-854, 2015. 



Carbohydrate Chemistry

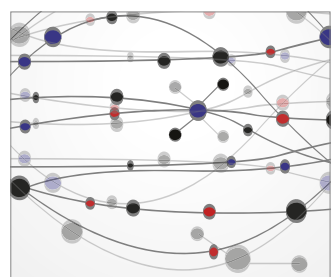

The Scientific World Journal

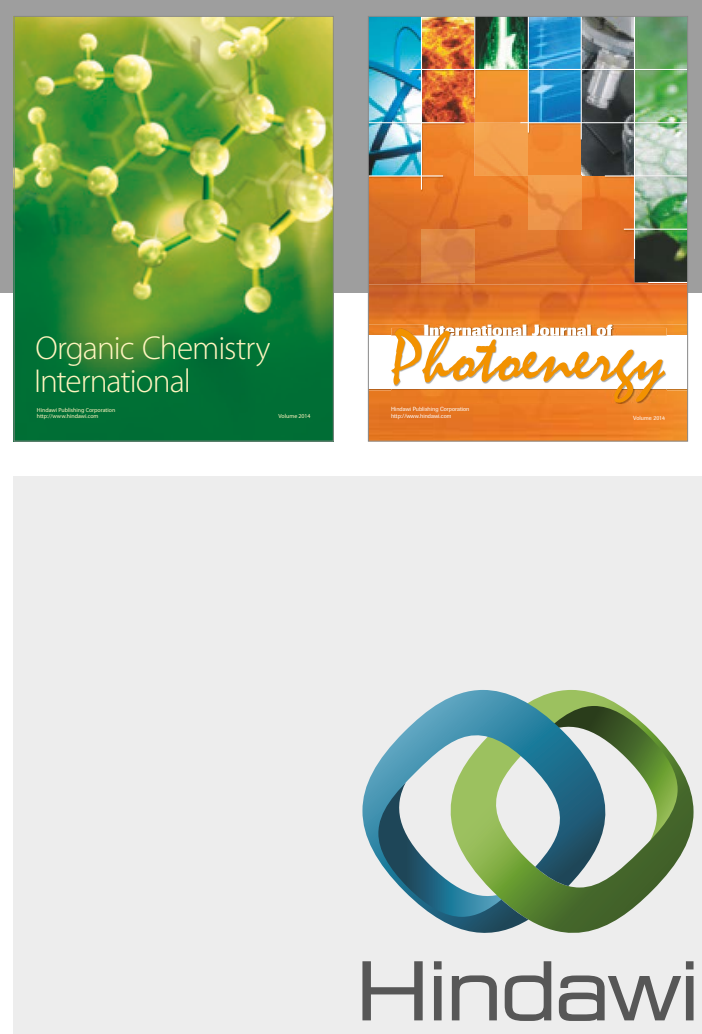

Submit your manuscripts at

https://www.hindawi.com

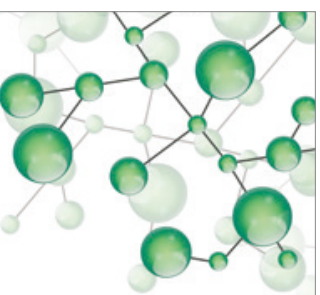

International Journal of

Inorganic Chemistry

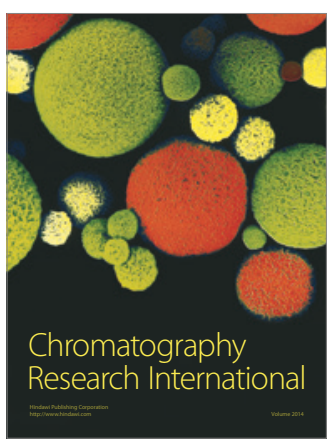

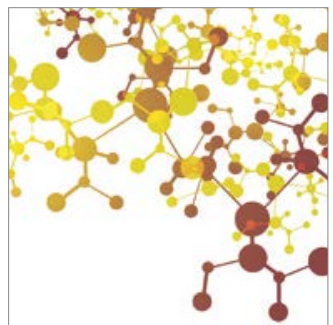

Applied Chemistry
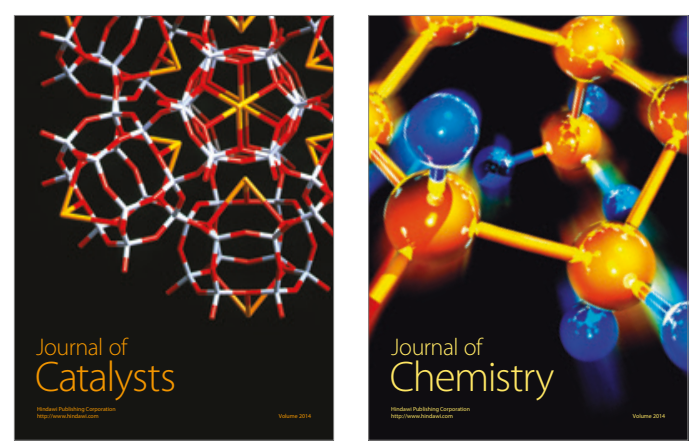
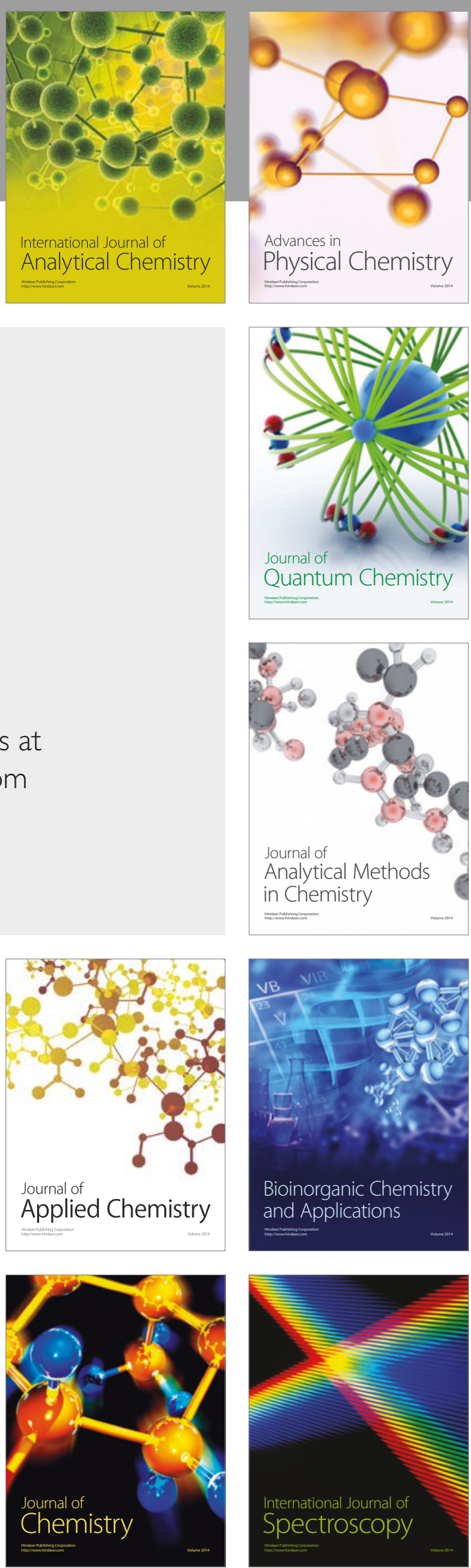